\title{
Familial exudative vitreoretinopathy associated with familial thrombocytopathy*
}

\author{
P. R. ChaudhuRi, A. R. ROSENTHAL, D. B. GOUlSTine, D. ROWLANDS, AND \\ V. E. MITCHELL
}

From the Departments of Ophthalmology and Haematology, University of Leicester School of Medicine

SUMMARY Two families with familial exudative vitreoretinopathy were studied in which platelet aggregation defects were found in all the affected members. The major defect observed was absent platelet aggregation with arachidonic acid. In addition platelet aggregation with collagen and adrenaline was reduced in one severely affected member. The implication of the platelet aggregation defect in the pathogenesis of this retinal vascular disorder is discussed.

Familial exudative vitreoretinopathy (FEVR) was first described by Criswick and Schepens in 1969. ${ }^{1}$ Later Gow and Oliver established that the condition was inherited as an autosomal dominant trait. ${ }^{2}$ The clinical features of this disease closely resemble those of retrolental fibroplasia. ${ }^{12}$ The early changes consist of abrupt termination of the retinal blood vessels immediately beyond the equator, extensive areas of capillary closure anterior to the terminatioan of the retinal vessels, and development of retinal neovascularisation at the junction of the retinal vessels and the capillary free zone. ${ }^{2-4}$ Vitreous haemorrhage is often the presenting complaint.

The late changes consist of an elevated fibrovascular scar usually in the temporal periphery, dragging of the optic disc and macula, and the development of traction and rhegmatogenous retinal detachment. ${ }^{24}$ Recently Brockhurst et al. have described histopathological findings of a prominent vitreous membrane posterior to the ora serrata in the advanced stages of the disorder. ${ }^{5}$

In this study 2 families with FEVR are described in which associated platelet aggregation defects in the affected members of the family were also demonstrated. The implications of this haematological abnormality in the pathogenesis of retinal neovascularisation are discussed.

\footnotetext{
*Presented at the Association for Research in Vision and Ophthalmology Annual Meeting, Sarasota, Florida, 3 May, 1982.

Correspondence to Mr P. Ray Chaudhuri, Department of Ophthalmology, Clinical Sciences Building, Leicester Royal Infirmary, PO Box 65, Leicester LE2 7LX.
}

\section{Materials and methods}

Two families with FEVR have been studied. The pedigrees of these families are portrayed in Fig. 1. Family I consists of a sister (family IA), her brother (family IB) and their respective children. In family IA none of the members had any obvious clinical or fluorescein angiographic evidence of the disease, though fluorescein angiographic studies on the sister, which were examined by 2 other independent observers, were equivocal. In family IB the brother and 4 of his children were affected. In family II the father and his only son had the disorder.

Typical fundus changes of FEVR are shown in Fig. 2. Figs. 3 and 4 demonstrate the fluorescein angio-

Family I

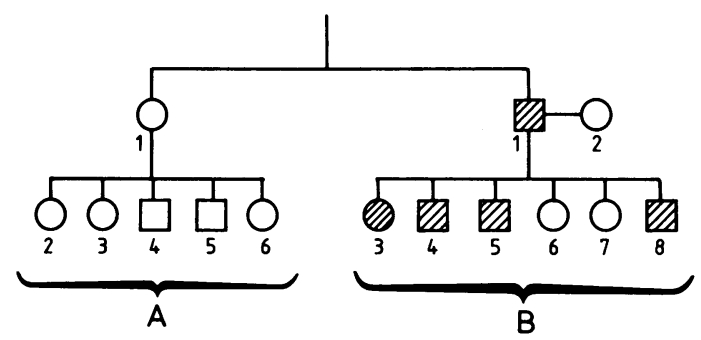

Family II

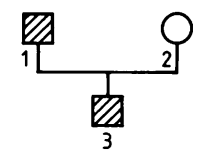

Fig. 1 The pedigrees of 2 families with FEVR. 


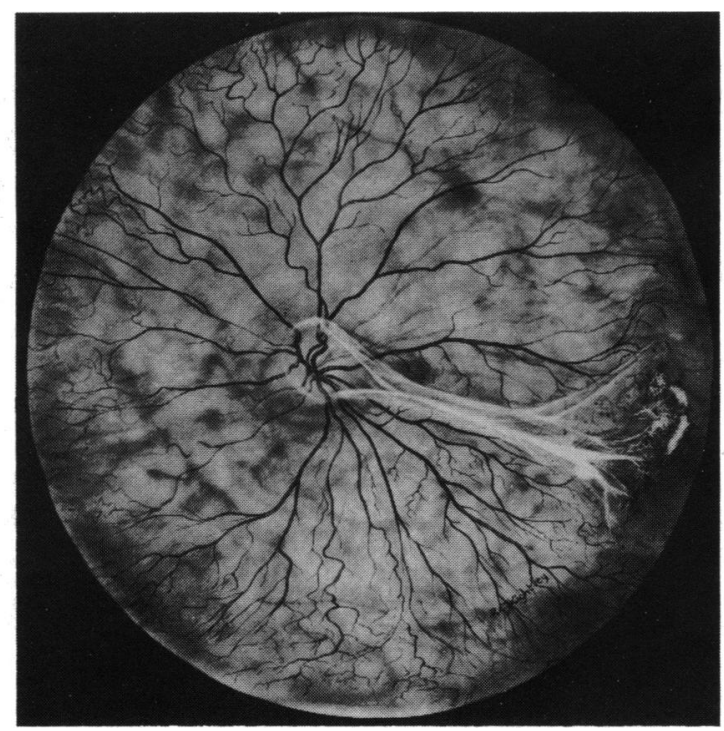

Fig. 2 Fundus of left eye of patient IB4. Note dragging of optic disc and fibrous epiretinal membrane extending from disc to temporal equator, where it ends in a fibrovascular mass.

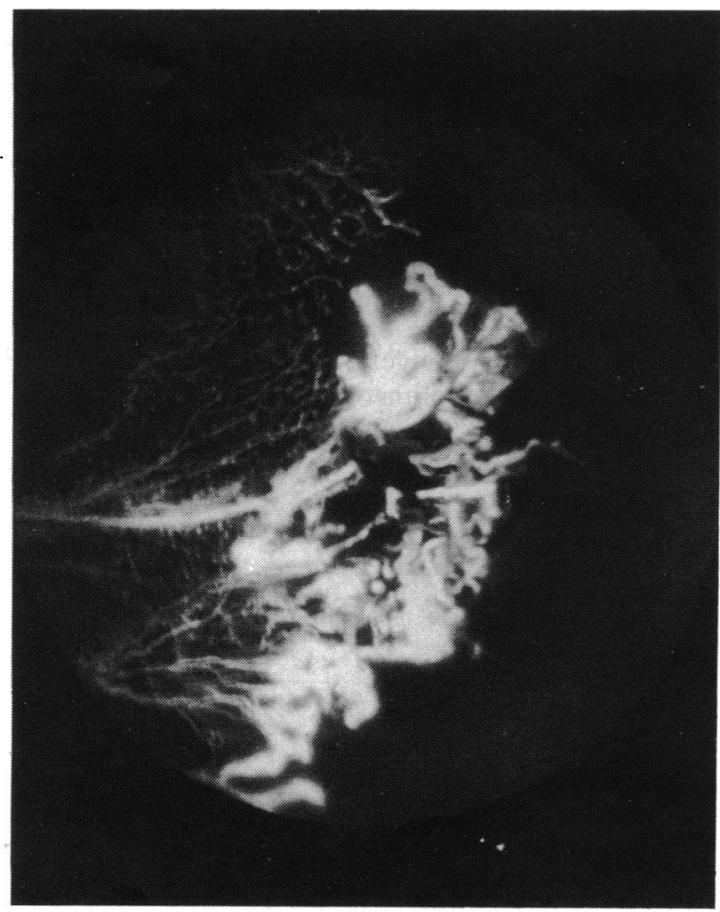

Fig. 3 Fluorescein angiographic changes of the temporal periphery of left eye of patient IB4. Note extensive abnormal arborisation of retinal arterioles ending at equator, extensive areas of capillary closure, and a large frond of retinal neovascularisation. graphic appearance of the retinal vascular abnormalities observed in the left and right eye respectively of patient IB4.

Haematological studies were carried out in all members of the 2 families. These included plasma viscosity, haematocrit, platelet count, and platelet aggregation tests. The platelet aggregation studies consisted of platelet aggregation with $1.5 \mathrm{mM}$ and $0.75 \mathrm{mM}$ arachidonic acid, $1 \mu \mathrm{g}$ adrenaline, high (4 $\mu \mathrm{g})$ and low $(1 \mu \mathrm{g})$ dose collagen, ADP and $1.5 \mathrm{mg}$ ristocetin. The haematological investigation was done 'blind' with respect to the ophthalmological status of the patients. $0.75 \mathrm{mM}$ arachidonic acid was used only when results of platelet aggregation with $1.5 \mathrm{mM}$ arachidonic acid were normal. None of the patients had taken aspirin or other antiplatelet drugs before the tests.

\section{Results}

The results of platelet aggregation studies are given in Tables 1, 2, and 3. Platelet aggregation with $1.5 \mathrm{mM}$ arachidonic acid was absent in all the affected members in family IB (Table 1). Platelet aggregation with $1 \mu \mathrm{g}$ collagen and $1 \mu \mathrm{g}$ adrenaline was also

Table 1 Platelet aggregation studies in family IB

\begin{tabular}{|c|c|c|c|c|}
\hline \multirow[t]{2}{*}{ Patient } & \multirow{2}{*}{$\begin{array}{l}\text { Severity } \\
\text { of FEVR }\end{array}$} & \multicolumn{3}{|c|}{ Platelet aggregation } \\
\hline & & $\begin{array}{l}1.5 \mathrm{mM} \\
\text { arachidonic } \\
\text { acid }\end{array}$ & $\begin{array}{l}\text { leg } \\
\text { collagen }\end{array}$ & $\begin{array}{l}1 \mu g \\
\text { adrenaline }\end{array}$ \\
\hline IB1 & + & Absent & $\mathbf{N}$ & $\mathbf{N}$ \\
\hline IB2 & 0 & $\mathbf{N}$ & $\mathbf{N}$ & $\mathbf{N}$ \\
\hline IB3 & +++ & Absent & $\mathbf{N}$ & $\mathbf{N}$ \\
\hline IB4 & ++ & Absent & $\mathbf{N}$ & $\mathbf{N}$ \\
\hline IB5 & + & Absent & $\mathbf{N}$ & $\mathbf{N}$ \\
\hline IB6 & 0 & $\mathbf{N}$ & $\mathbf{N}$ & $\mathbf{N}$ \\
\hline IB7 & 0 & $\mathbf{N}$ & $\mathbf{N}$ & $\mathbf{N}$ \\
\hline IB8 & ++++ & Absent & $\downarrow$ & $\downarrow$ \\
\hline
\end{tabular}

$0=$ No apparent disease. $\mathrm{N}=$ Normal. $\downarrow=$ Decreased.

Table 2 Platelet aggregation studies in family IA

\begin{tabular}{|c|c|c|c|}
\hline \multirow[t]{2}{*}{ Patient } & \multirow{2}{*}{$\begin{array}{l}\text { Severity of } \\
\text { FEVR }\end{array}$} & \multicolumn{2}{|c|}{ Platelet aggregation } \\
\hline & & $\begin{array}{l}1.5 \mathrm{mM} \\
\text { arachidonic } \\
\text { acid }\end{array}$ & $\begin{array}{l}1 \mu g \\
\text { collagen }\end{array}$ \\
\hline $\begin{array}{l}\text { IA1 } \\
\text { IA2 } \\
\text { IA3 } \\
\text { IA4 } \\
\text { IA5 } \\
\text { IA6 }\end{array}$ & $\begin{array}{l}\mathbf{0} \\
\mathbf{0} \\
\mathbf{0} \\
\mathbf{0} \\
\mathbf{0} \\
\mathbf{0}\end{array}$ & $\begin{array}{l}\text { Absent/N* } \\
\mathbf{N} \\
\mathbf{N} \\
\text { Absent/absent } \\
\mathbf{N} \\
\mathbf{N}\end{array}$ & $\begin{array}{l}\mathbf{N} \\
\mathbf{N} \\
\mathbf{N} \\
\downarrow \\
\mathbf{N} \\
\mathbf{N}\end{array}$ \\
\hline
\end{tabular}

$0=$ No apparent disease. $\mathrm{N}=$ Normal. $\downarrow$ = Decreased.

${ }^{*}$ Analyses performed on 2 separate occasions. 

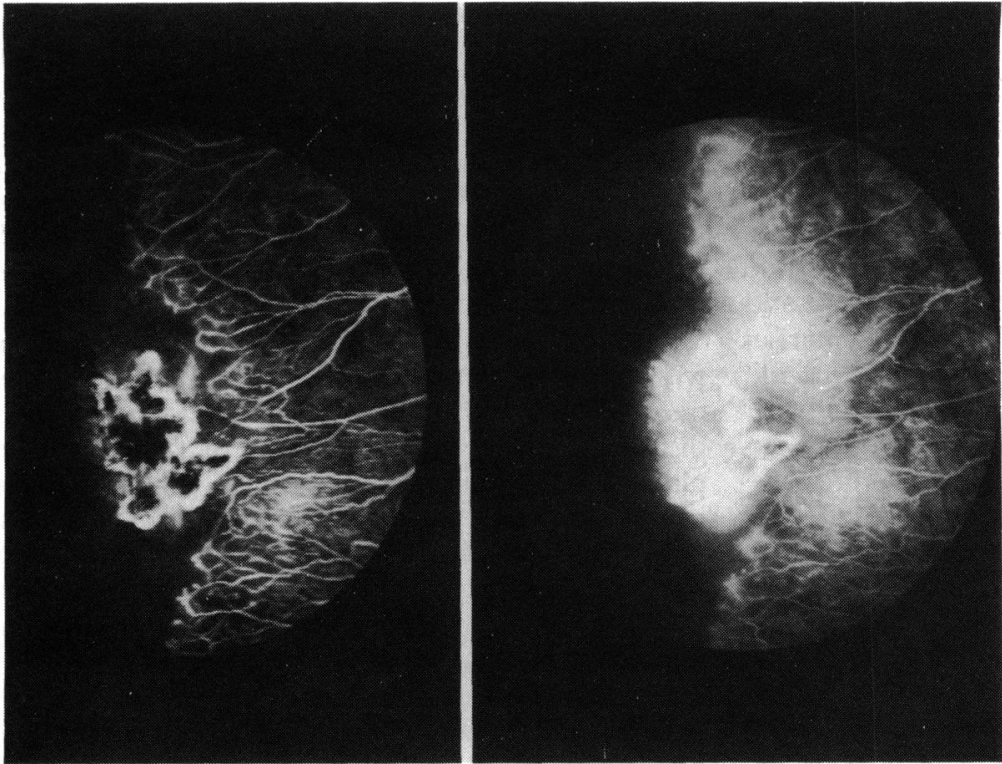

Fig. 4 Early (left) and late (right) fluorescein angiographic changes of temporal periphery of right eye of patient IB4. Note characteristic abrupt ending of retinal vessels, capillary closure, and frond of retinal neovascularisation.

reduced in one of the affected children who had very severe retinal disease. All the other platelet aggregation studies were normal. In family IA (Table 2) platelet aggregation with $1.5 \mathrm{mM}$ arachidonic acid was absent on one occasion and normal on another occasion in the mother and absent on 2 occasions in one of her sons. In the latter case platelet aggregation with $1 \mu \mathrm{g}$ collagen was also reduced. Platelet aggregation with all the other reagents were normal. In family II (Table 3 ) platelet aggregation with 1.5 $\mathrm{mM}$ arachidonic acid was normal, but with $0.75 \mathrm{mM}$ arachidonic acid platelet aggregation was absent in the 2 affected members of the family. All other platelet aggregation studies were normal in family II. All other haematological studies performed in these 2 families were normal.

\section{Discussion}

FEVR is a disorder in which peripheral retinal obliteration of varying severity is inherited as an autosomal dominant condition. The disease may be

Table 3 Platelet aggregation studies in family II

\begin{tabular}{|c|c|c|c|}
\hline \multirow[t]{2}{*}{ Patient } & \multirow{2}{*}{$\begin{array}{l}\text { Severity of } \\
\text { FEVR }\end{array}$} & \multicolumn{2}{|c|}{ Platelet aggregation } \\
\hline & & $\begin{array}{l}0.75 \mathrm{mM} \\
\text { arachidonic } \\
\text { acid }\end{array}$ & $\begin{array}{l}1.5 \mathrm{mM} \\
\text { arachidonic } \\
\text { acid }\end{array}$ \\
\hline II1 & + & Absent & $\mathbf{N}$ \\
\hline II 2 & 0 & $\mathbf{N}$ & $\mathbf{N}$ \\
\hline II3 & +++ & Absent & $\mathrm{N}$ \\
\hline
\end{tabular}

$0=$ No apparent disease. $\mathrm{N}=$ Normal. asymptomatic and mild, indicating variable expressivity. Peripheral retinal vascular changes are best identified in the early stages by fluorescein angiography. ${ }^{4}$ The sharply demarcated zone of peripheral retinal blood vessel closure, the pattern of arteriovenous anastomosis, and the dragging of the optic disc are remarkably similar to the fundal changes observed retrolental fibroplasia. In view of these similarities the disease may easily be misdiagnosed in children.

Ober et al. have suggested similarities in the pathological mechanisms between FEVR and retrolental fibroplasia, though the aetiopathogenesis of this disease remains unknown. ${ }^{4}$ The significance of defective platelet aggregation with arachidonic acid in all the affected patients in our families is not known. Though some laboratories may find decreased aggregation in a proportion of 'normal' controls, even when asprin is rigorously excluded, we feel that the association reported herein is real, as

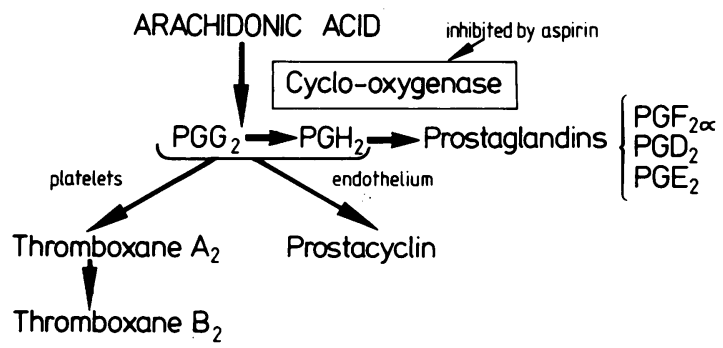

Fig. 5 Schematic representatioan of the various pathways of arachidonic acid metabolism. 
these analyses were performed under strictly controlled and identical conditions each time they were undertaken. In addition the almost exact correlation between abnormal platelet aggregation and presence of clinical disease suggests that the association is valid.

A review of arachidonic acid metabolism is presented in an attempt to clarify the possible association between platelet aggregation defects and retinal vascular obliteration. Fig. 5 summarises the metabolic pathways of arachidonic acid. ${ }^{\circ}$ Arachidonic acid is a component of the membrane phospholipids of cells and is converted to prostaglandin endoperoxide, $\mathrm{PGG}_{2}$, in the presence of the enzyme cycloosygenase, which is inhibited by aspirin. $\mathrm{PGG}_{2}$ is then converted to another prostaglandin endoperoxide, $\mathrm{PGH}_{2}$, which is then broken down to stable prostaglandins $\mathrm{PGF}_{2}$ alpha, $\mathrm{PGD}_{2}$, and $\mathrm{PGE}_{2}$.

Prostaglandin endoperoxides $\mathrm{PGG}_{2}$ and $\mathrm{PGH}_{2}$ are converted enzymically into 2 other unstable products, thromboxane $A_{2}$ and prostacyclin. In the platelets the prostaglandin endoperoxides are metabolised to thromboxane $\mathrm{A}_{2}$ by thromboxane synthetase. Platelet thromboxane $A_{2}$ is a potent inducer of platelet aggregation as well as a potent vasoconstrictor. It is unstable and is rapidly broken down into thromboxane $B_{2}$, a stable and assayable end product. In the endothelium the prostaglandin endoperoxides are metabolised to prostacyclin, which is a potent vasocilator and antiplatelet aggregator.

Flower et al. ${ }^{7}$ in their studies of puppies with retrolental fibroplasia have suggested that thromboxane $A_{2}$, which is a potent vasoconstrictor, has a protective role on the immature retinal blood vessels. As FEVR closely resembles retrolental fibroplasia, it is therefore possible that thromboxane $A_{2}$ may have a role in the development of this disorder. If a deficiency of thromboxane $A_{2}$ existed in FEVR, inadequate retinal vasotonia would result, which would fail to protect immature retinal blood vessels at birth, when normally blood oxygen tension and blood pressure suddenly rise. It is therefore important to determine whether or not such a deficiency of thromboxane $A_{2}$ production as a consequence of the defective arachidonic acid metabolism exists in FEVR. This is currently being undertaken in our laboratory.

The significance of reduced platelet aggregation with $1 \mu \mathrm{g}$ collagen and $1 \mu \mathrm{g}$ adrenaline in one member of family IA who had the most severe disease is unknown. In fact whether any of the platelet aggregation defects have a definite role to play in the pathogenesis of this disorder requires further clarification. Further families with FEVR need to be studied to establish whether or not the thrombocytopathy exists in constant association with the ophthalmic disorder.

We thank Miss K. Kirwan for photographic assistance, Mr R. Kightley for contributing the artwork, and Mrs J. Wood for her secretarial skills.

References

1 Criswick VG, Schepens CL. Familial exudative vitreoretinopathy. Am J Ophthalmol 1969; 68: 578-94.

2 Gow J, Oliver GL. Familial exudative vitreoretinopathy: an expanded view. Arch Ophthalmol 1971; 86: 150-5.

3 Canny CLB, Oliver GL. Fluorescein angiographic findings in familial exudative vitreoretinopathy. Arch Ophthalmol 1976; 94: 1114-20.

4 Ober RR, Bird AC, Hamilton AM, Sehmi K. Autosomal dominant exudative vitreoretinopathy. Br J Ophthalmol 1980; 64: 112-20.

5 Brockhurst RJ, Albert DM, Zakov N. Pathologic findings in familial exudative vitreoretinopathy. Arch Ophthalmol 1981; 99: 2143-6.

6 Moncada S, Vane JR. Unstable metabolites of arachidonic acid and their role in haemostasis and thrombosis. Br Med Bull 1978; 34: 129-35.

7 Flower RS, Blake DA, Wajer SD, et al. Retrolental fibroplasia: evidence for a role of the prostaglandin cascade in the pathogenesis of oxygen induced retinopathy in the newborn beagle. Pediatr Res 1981; 15: 1293-302. 